IBT Journal of Business Studies

Volume 14(2), 187-197, 2018

\title{
Challenges of The Education System of Pakistan: Especially Featuring Adult Literacy and Enrolment Rate of Pakistan
}

\author{
Kinza Zafar Sheikh ${ }^{l}$ \\ Muhammad Waqas ${ }^{2}$ \\ Muhammad Shahid Khan ${ }^{3}$
}

\begin{abstract}
This Study is unfolding the challenges that Pakistan education system has been facing. Education is the key factor when we talk about leadership and development it not only develops the person but also moves the country towards progression in terms of economic, political and social improving the standards of living. Till now education at every level prepares the person for the next level till it takes the person to tertiary industry, hence there is a close connection with education and development of Pakistan, apparently, the indicator doesn't reflect very positive results. There is an untrained teaching staff with fluctuating enrollments and low resource facilitation, a dual medium of instruction, weak examination system and government that allocates low budget towards education system. Moreover, there is a lack of research which promotes new ways to handle decision and gender disparity is also seen these problems that can't be overlooked, hence this topic is selected as a domain to work on and provide possible suggestions to overcome.
\end{abstract}

Keywords: Literacy rate, Economic Growth, Challenges, Education system, Development.

1- $\quad$ Student, DHA Suffa University, Karachi, Pakistan, kinza zafar42@yahoo.com

2- Lecturer DHA Suffa University, Karachi, Pakistan, mwaqas.aerc@gmail.com

3- Assistant Professor, PhD, DHA Suffa University, Karachi, Pakistan. 


\section{INTRODUCTION}

It is evident to accept the fact that education is the backbone for the development of any nation. The prior state of nations reflects how from the support of education they have led towards the progression of some good examples of these are China, Bangladesh, Germany, South- Korea, Nepal, and the Maldives. Economists regard education as an important ingredient

To human capital apart from training, skills and health care (Khan, 2008). Education eradicates illiteracy and promotes employment, creating a sense of responsibility among the citizens followed by countries' economic growth to sustainable economic growth which is the aim of every country; to maintain stable GDP growth, with both effective fiscal and monetary policy implementation (Ahmaed, 2014). Education creates the urge to know and teach our children the petty value of status quo via education. Its basic purpose is to create an individual teach how to make a livelihood by honesty which is possible through the spread of education (din, 2013). Another developing trend is that the predominance of knowledge economy over agriculture, manufacture, and government. Industry and administration. Innovation, connectivity, and information explosion have changed the course of economic growth. A country that implements its population with the mental ability of education moves towards progression. Last six decades proves that economic development is correlated with the status of education of the country. one year of additional education of labor force enhances hundreds of one thousand millions of rupees in greater production of commodities and services (Hussain, 2012) It's also true there are no drastic changes seen by education but it largely affects the company. Largely affects the society. It is a fact that a proper education system contributes to stable political, economic and social conditions of a state Pakistan; a developing country with a weak economy and unstable political conditions, with approximately 180,1 million people, (Ashraf, Azeem 2016)\}, with Pakistan being 6th most populous country in the world (source; internetworldsats.com). Pakistan education system has 303, 446institutions and catering 47,491,260 students and 1,723,790 teachers having 191,065public institution and 121, 3811 private institutions. According to the constitution of Pakistan the state will provide free primary and secondary education to the students falling in the age group 5-16 whereas, Real picture of providing education is much different with regard to the constitution of Pakistan, education is the basic right of every human living but sadden to know that education here has been a deprived sector. Pakistan has signed sustainable development goals, the agenda of which one of the goals relates to quality and lifelong learning. It is a fact that a proper education system leads to stable political, economic and social conditions of a country and leads to leadership the education system of Pakistan is not that effective which has resulted in the frustrated society with the generation moving directionless (Ahmaed, 2014). Though it adopted more than 25 policies the literacy rates fails to reach fails to stand near other south Asian countries; Bangladesh, Sri Lanka. NEP National Education Policy was a step took by the government to remove illiteracy and provide basic education and expected to attain $100 \%$ enrollment and $86 \%$ literacy rate for age till 10. (Ashraf, 2016) The education sector of Pakistan has more than 150,000 public institutions serving more than 21 million students and huge private sector serving another 12 million of population has alarming challenges (Dr. Khalid Rashid, November 2012). 


\section{Literacy Rate in percentage (Latest)}

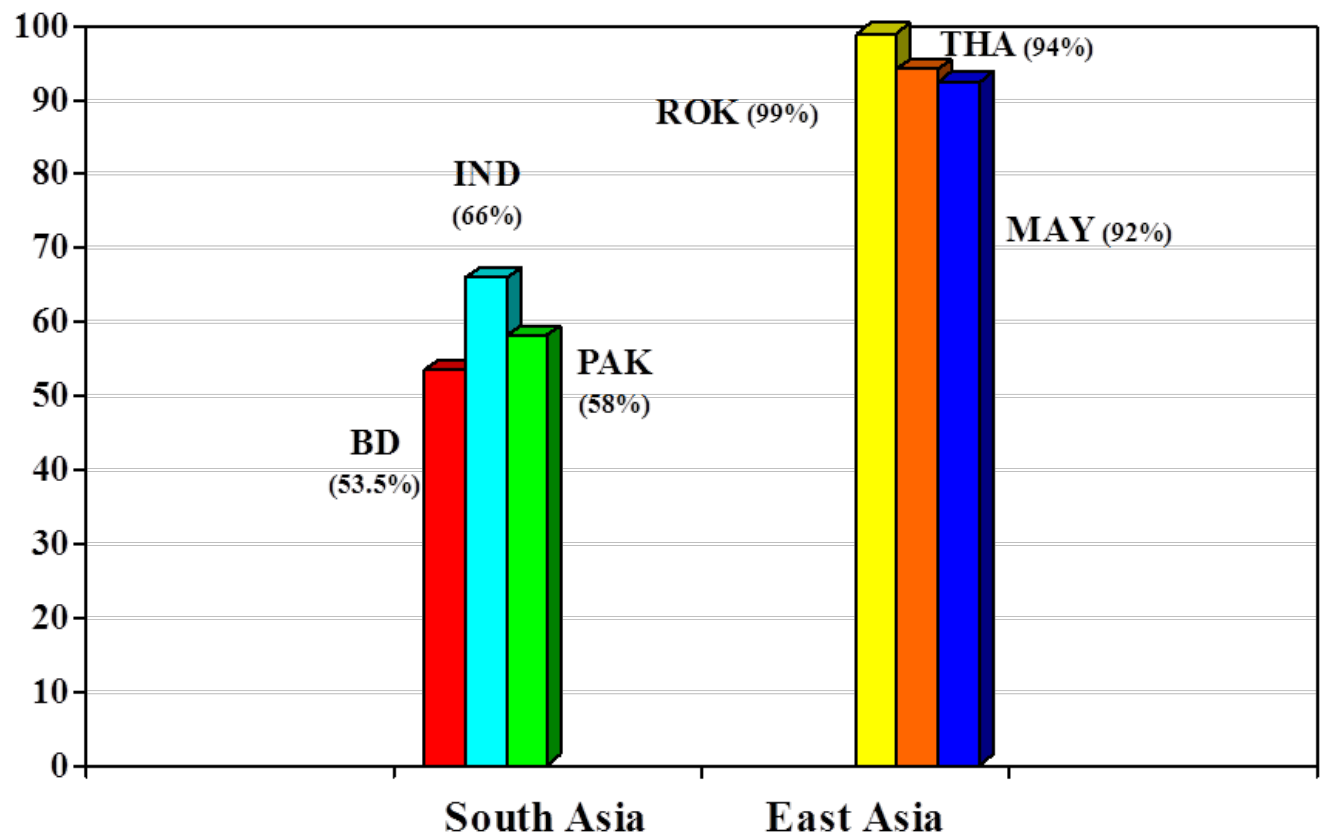

Education is the right of everyone in Pakistan, here; in Pakistan, there is no look over the education system from poor infrastructure to outdated curricula, whether be financial inputs or implementing policy all are inadequate. Children here only dream to go to school because child labor is a setback. We can't expect the literacy rate to increase. Nevertheless, fee structures are the unbearable burden. There are many problems highlighted in detail further in this research paper.

The aim of the study is to explore the determinants of low literacy rate in Pakistan, and also what measures the government should take to make education system efficient with significant improvement in literacy rate?

This is a quantitative study based on secondary data, highlighting the challenges in the education; there is less financial support, inefficiency in implementing policies, with no proper look over(Rasool, 2007) every child deserves quality of education to rise above, there are several problems that Pakistan face in educational sector from teachers to curriculum government various steps and has to come up with more strategies to overcome the current situation (Chisti, 2011)

There has been a change in Pakistan's literacy rate four and a half times since 1951 but the female literacy rate is really alarming (Zaidi, 2015). This study will help to create a framework to run education system in a way to achieve a positive trend to literacy rate which in turn will help the country to run at its full capacity as education is an important indicator for countries economic development.

This is a descriptive study to explore the major hurdles associated with education sector development. The major Indicators that are investigated to understand the education system of Pakistan are the adult 
literacy rate, dropout rates, male and female enrollment rate, resources allocation, number of absenteeism of teachers and students. With the contingent of the indicators relies on the data.

Time is a major constraint in this study following with the availability of data, with those financial constraints restricted not to work on primary data.

\section{LITERATURE REVIEW}

Education promotes leadership in society and helps in development. It improves the life of the country in all aspects. Secondary and university education prepares the citizens for the industrial development which proves that education and development are closely related. In Pakistan the development indicators after 5 decades are not showing positive trends there are a lot of difficulties that students here face in quality of teachers, students, library, equipment, financial crisis, ineffective government and academic results are not to international standards(Rasool, 2007).

Investment in human capital is way to progression of the nation there are various stumbling blocks which ends up decreasing effectiveness of education sector, in which factors that cost count are low adult literacy rate, inequalities in rural and urban areas, high dropout rate, cost of education and lack of parental concerns which are followed with some other determinants of absenteeism of teaching staff, irrelevant curricula and conservative attitude towards girls education quantitative data of Multan proved high cost of education with decentralized decision making are major issues and government should impose more policies on education rather than largely working on infrastructures. (Sattar, 2012 March).

The study suggested how education strengthens women in Pakistan, a study was done to address understudies female and female employee from 10 state-funded colleges of Pakistan; 1290 understudies and 290 employees reacted. Along these lines, semi-structured interviews were held with 10 employees and 10 understudies. Respondents featured monetary autonomy and an expanded remaining inside family and society as the primary advantages of advanced education support. A noteworthy finding is that cooperation in advanced education empowers ladies to effect on various oppressive practices at the same time and subsequently impact improves. The fundamental suggestion is that future instructive methodologies be produced with the point of further advancing gender equity in every aspect of training in Pakistan, however especially with the point of expanding female understudies' support in advanced education .

An effective school is where the academic output, competencies, skills and behavior goal is achieved. A survey method was used to know how gender difference and school effectiveness are related in terms of the teaching staff, administrator and curriculum experts, results showed professionalism to be an important factor in terms of availabilityand head following with the scarce resource in the school (Farhat Saleem, December 2013).

English is counted to be as the tool to achieve modernization, technology and to move towards advancement proficiency in the English language improves the discourse of quality of education it is discussed along with the medium used in the classroom where assessment data is analyzed to see how effectively the policies are implied. Here private schools are termed as English medium schools where the English language is on focus parents of idle class who find it expensive they too prioritize to enroll their children to these schools rather than the state own school where medium of communication is Urdu this reflects the complex education system of Pakistan based on a three-tier governance this is the point where policy making and implementation becomes difficult.(Shamim, 2008).

Education system of Pakistan has not been that strong and effective Pakistan has been facing a lot of 
instability in terms of development, political and social as well to all these one major reasons is the illiteracy which should be looked down seriously some issues that are highlighted in the research are; outdated curricula, low budget, examination system, lack of quality of teachers, directionless education. (Ahmaed, 2014).

Inadequate implementation of educational policy is one of the core reasons for very little development in education. Every time a new policy is made without regarding the cause of the failure of the previous one. The 5-year developmental plans were found to be the unrealistic lie the educational reforms with unmet goals and extending dates. Educational plans show the government wants its officials to provide jobs. According to the 7 th plan, only $7.3 \%$ was spent on education out of which only $1.3 \%$ on the English plan which is quite alarming. The paper reflected the poor consideration towards education and not learning from past experiences these are the reasons why in the last two decades average literacy rate has increased slightly over $1 \%$ and needs a lot of work and time to achieve $100 \%$ literacy rate(Ahsan, 2003).

Since independence efforts are being made to make education system relevant to country's situations, the objective of education is set keeping in mind the educational policies which are; $t$ make amendments in the education system with the social needs of economics and political stability. To bring unity and patriotism, provide equal opportunities to promote the ethical and religious views. (Hina Rehman, 2011).

Students in Pakistan are focused to learn and memorize in school rather than being focused on the need to polish and learn skills like decision making and problem-solving which becomes a major part of their life in future. The state of citizenship education is less, the research indicates that there is no difference between Islamic education and citizen education on the basis of curriculum and textbooks with the suggestion to add this to teacher education program as they are one of the major sources to spread education (Dean, 2005).

The education system of Pakistan lacks solidarity and distribution after so many years of independence and policies as well. The educational indicator has been saddening in here with low literacy rates, ghost's schools, with primary level rate to $73 \%$ which falls to $24 \%$ in secondary schools with the low administration. Unless the structure of educational policies is clearly understood in right directions any amount of financial and human aid won't be able to develop an improving education system. (Kazm, 2005).

\section{CHALLENGES OF EDUCATION}

\section{Teachers}

Teachers are the top tier when it comes to education teachers hired should be qualified, which indicates that any teacher hired should have a 10 -year degree with 11 months certification program for being a primary school teacher, there are no surety institutions following this while hiring teachers. (Rasool, 2007) Apart from this teachers play the leading role, their remuneration should be under consideration which is not that optimized. The remote areas are said to have no teachers as well.

\section{Development of Teachers}

Schools should look over the training and developing of the teachers which increases the quality of the teacher and enhance their skills. There are less training opportunities for teachers in Pakistan though there are training centers for all this needs funds to work. Most teachers are not aware of how to plan lessons and guide children in problem-solving or helping out in libraries or other extra-curricular 
activities. There is no training on how to deliver lessons according to the strength of children where children are more encouraged to memorize and pass the exam. (Ahmaed, 2014).

\section{Gender Disparity}

Women should equally be the part of education not from the sense to be the bread earner or equality in terms of men but with the sense of responsibility of better parenting educations makes one feel empowered the rate of female literacy rate is $60 \%$ with that of male $84 \%$. (Rasool, 2007), 56\% education facilitation is provided to males as compared to $44 \%$ female students.

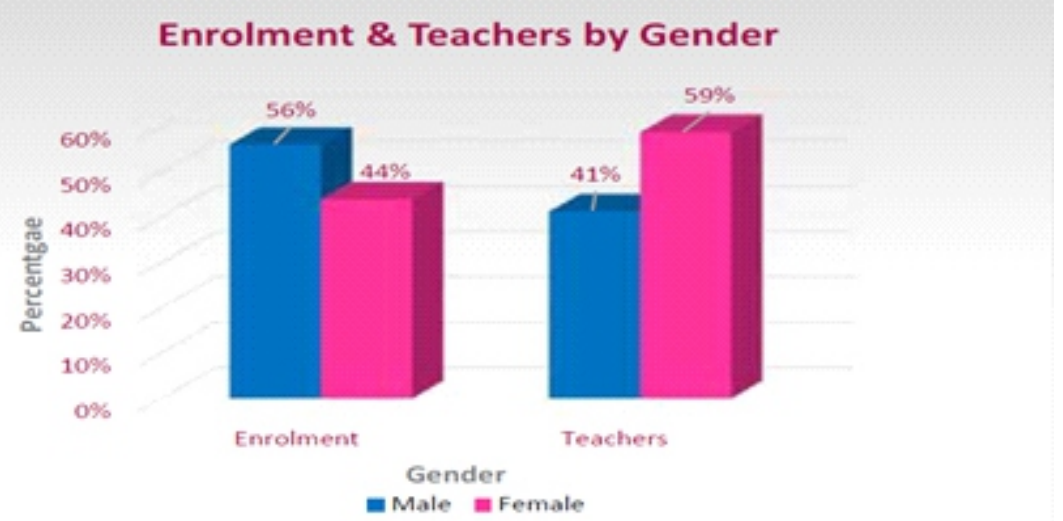

Figure.1: Pakistan Education Statics 2016

\section{Class Strength}

This is another factor primary school classroom have students more than the capacity of the class whether government or private school with a single teacher looking over a huge class which becomes the reason of poor quality of education and low maintenance of class decorum.

\section{The medium of Instruction:}

This is a dilemma that goes on whether the medium should be English or Urduas no uniformity is seen where state-owned schools use Urdu as the medium of instruction with their regional languages also being the part of the curricula, whereas private school promote English and also teach Urdu compulsorily till secondary education. The middle-class people are sacrificing on their need so the children may be part of the private school where the medium is English(Shamim, 2008) as far as Urdu is important for the development of country education medium should look over and be on the same page.

\section{Supervisory}

There is a fine line between being strict and harsh teachers often have harsh attitudes towards the students whether being private or government schools where teacher easily go to punish students in harsh sometimes beating and unacceptable manner demoralizing the student. This reflects the poor supervisory of the teachers. (Ahmaed, 2014). 


\section{Outdated Curriculum}

Unemployment in Pakistan has increased as the manpower in the market is not to be skillful its major reason is the context that has been teaching in schools with less opportunity for science and technology where both the subjects are at its verge in the market (Ahmaed, 2014). Proper school curriculum should be every school objective but the conditions in Pakistan are deplorable our present curriculum revolves around textbooks and subjects which are not even revised when it comes to stateowned schools with same old edition books going on and not updating with the advent of technology which has changed ways of education too. (Chisti, 2011)

\section{Resource Allocation:}

The infrastructure of schools are really poor with remote areas have no proper benches, stationary, electricity, water. The state-owned who have these are at very low maintenance, private schools fee structure is a high but scarce resource is rarely seen.

Moreover, the science education, in particular, have no good conditions where labs are inadequate with no or old apparatus and chemicals which needs to be settled on urgent basis for the good economic development of the country (Rasool, 2007)

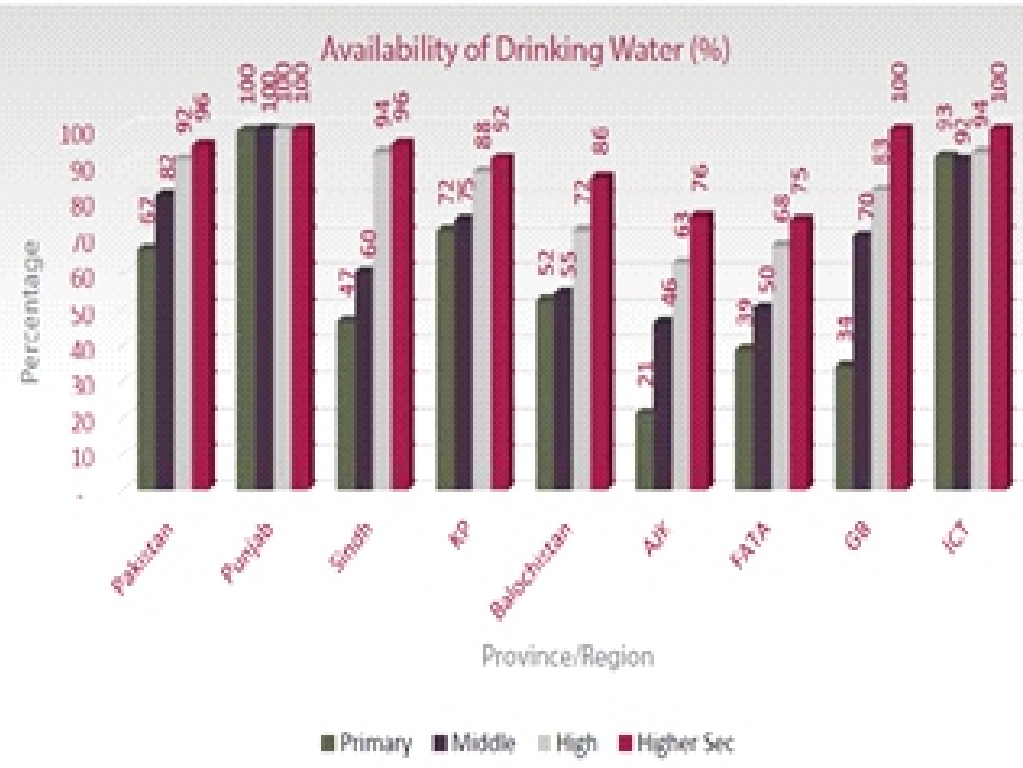

Figure.2: Pakistan Education Statics 2016

\section{Enrollment Rates}

Enrolling the students to acquire an education is evident but retaining the amount till secondary education is a challenge as the trend moves downwards from primary to secondary. The following table shows the enrollment of students from various schools and levels Economic survey of Pakistan showed a positive increase to $54 \%$ of literacy rate in 2005-6 which was $45 \%$ in 2001 and had increased other $6 \%$ in the last 10 years which dropped to by $2 \%$ pulling down the literacy rate to $58 \%$ for the year 2016-2017 as released by economic survey Pakistan. 


\begin{tabular}{|c|c|c|c|c|c|c|c|c|c|}
\hline & PRIMARY & & & MIDDLE & & & HIGH & & \\
\hline YEAR & BOYS & GIRLS & TOTAL & BOYS & GIRLS & TOTAL & BOYS & GIRLS & TOTAL \\
\hline 1994 & 7617864 & 4731235 & 12349099 & 2210029 & 1102207 & 3312236 & 895681 & 420421 & 1316102 \\
\hline 1995 & 7736894 & 4713666 & 12450560 & 2023742 & 975852 & 299542 & 840980 & 368367 & 1209347 \\
\hline 1996 & 9239034 & 6155962 & 15394996 & 2369253 & 1356896 & 3726149 & 1001194 & 520183 & 1521377 \\
\hline 1997 & 1006590 & 4699683 & 91706274 & 2249959 & 1153223 & 8403182 & 8105380 & 460459 & 1658399 \\
\hline 1998 & 1171972 & 5644968 & 91816941 & 4251176 & 9158645 & 4409822 & 3106402 & 463857 & 1702595 \\
\hline 1999 & 1210358 & 1704408 & 51914766 & 6249735 & 4161490 & 1411225 & 5107279 & 565298 & 1725723 \\
\hline 2000 & 9898232 & 6735775 & 16634007 & 2053767 & 1705558 & 3759325 & 889459 & 675466 & 1564925 \\
\hline 2001 & 9962751 & 6968109 & 16930860 & 2315127 & 1506088 & 3821215 & 929821 & 644343 & 1574164 \\
\hline 2002 & 1029759 & 6730738 & 91760498 & 5236683 & 6155131 & 0391814 & 693137 & 365753 & 1588912 \\
\hline 2003 & 9601462 & 6605824 & 16207287 & 2584043 & 1737218 & 4321261 & 109059 & 970899 & 1799591 \\
\hline 2004 & 1003944 & 1721850 & 71725794 & 8268785 & 1186262 & 2455047 & 311237 & 207563 & 1880021 \\
\hline 2005 & 9546629 & 7287788 & 16834417 & 3093313 & 2169010 & 5262323 & 121505 & 888195 & 2133008 \\
\hline 2006 & 9625483 & 7416454 & 17641937 & 3126496 & 2241112 & 5367608 & 136582 & 194939 & 2315216 \\
\hline 2007 & 9692806 & 7535468 & 17228274 & 3106311 & 2256407 & 5362718 & 142857 & 699767 & 2426255 \\
\hline 2008 & 9630839 & 7574355 & 17205194 & 3074017 & 2272719 & 5346736 & 144861 & 4104306 & 2491681 \\
\hline 2009 & 9608981 & 7572313 & 17181294 & 3125219 & 2313391 & 5438610 & 147061 & 7105270 & 2523322 \\
\hline 2010 & 9441429 & 7452804 & 16894233 & 3179378 & 2397056 & 5576434 & 149849 & 1076879 & 2568728 \\
\hline 2011 & 9807675 & 7759906 & 17567581 & 3391726 & 2561105 & 5952831 & 1559405 & 1132190 & 2691595 \\
\hline 2012 & 9832303 & 7742546 & 17574849 & 3496776 & 2628421 & 6119197 & 16470081 & 188318 & 2835326 \\
\hline 2013 & 9807675 & 7759906 & 17567581 & 3391726 & 2561105 & 5952831 & 15594051 & 132190 & 2691595 \\
\hline 2014 & 10249734 & 48119076 & 18369910 & 3649905 & 2769455 & 6419404 & 19337651 & 432473 & 3366238 \\
\hline 2015 & 10471338 & 88280657 & 18751995 & 3647602 & 2798095 & 8445697 & 19616271 & 475679 & 3437306 \\
\hline 2016 & 10722905 & 58628929 & 193518234 & 3664107 & 2862521 & 6526628 & 19122941 & 413238 & 3325532 \\
\hline
\end{tabular}

Table.1: Pakistan Education Statics

The graph below shows the enrollment comparison of gender at different levels

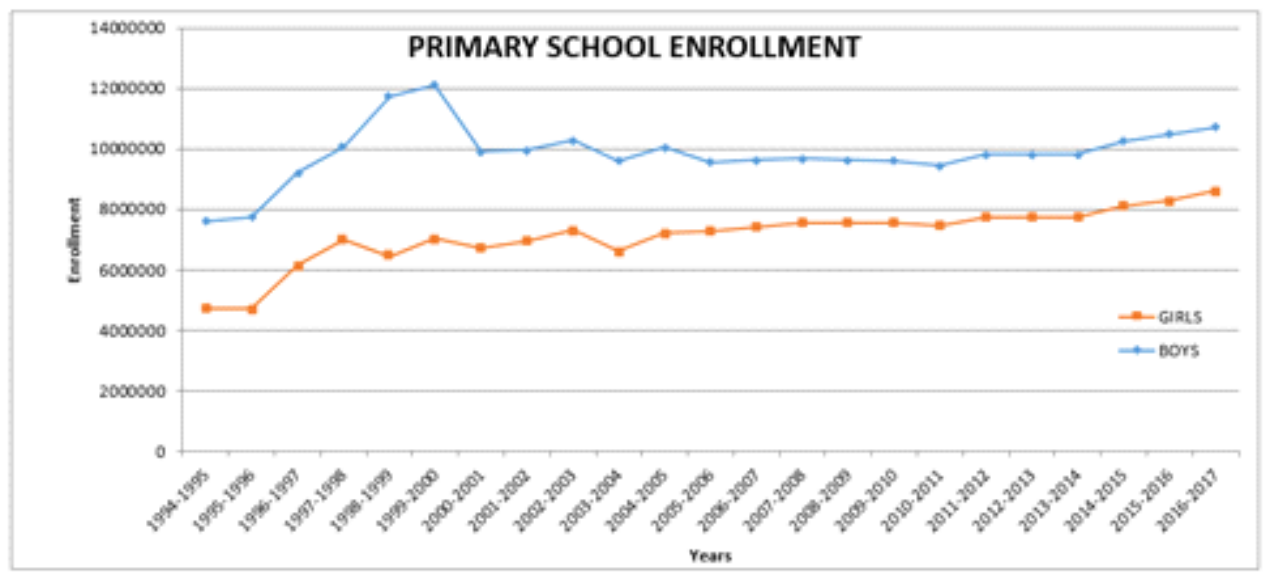

Figure.3: Pakistan Education Statics 2016 


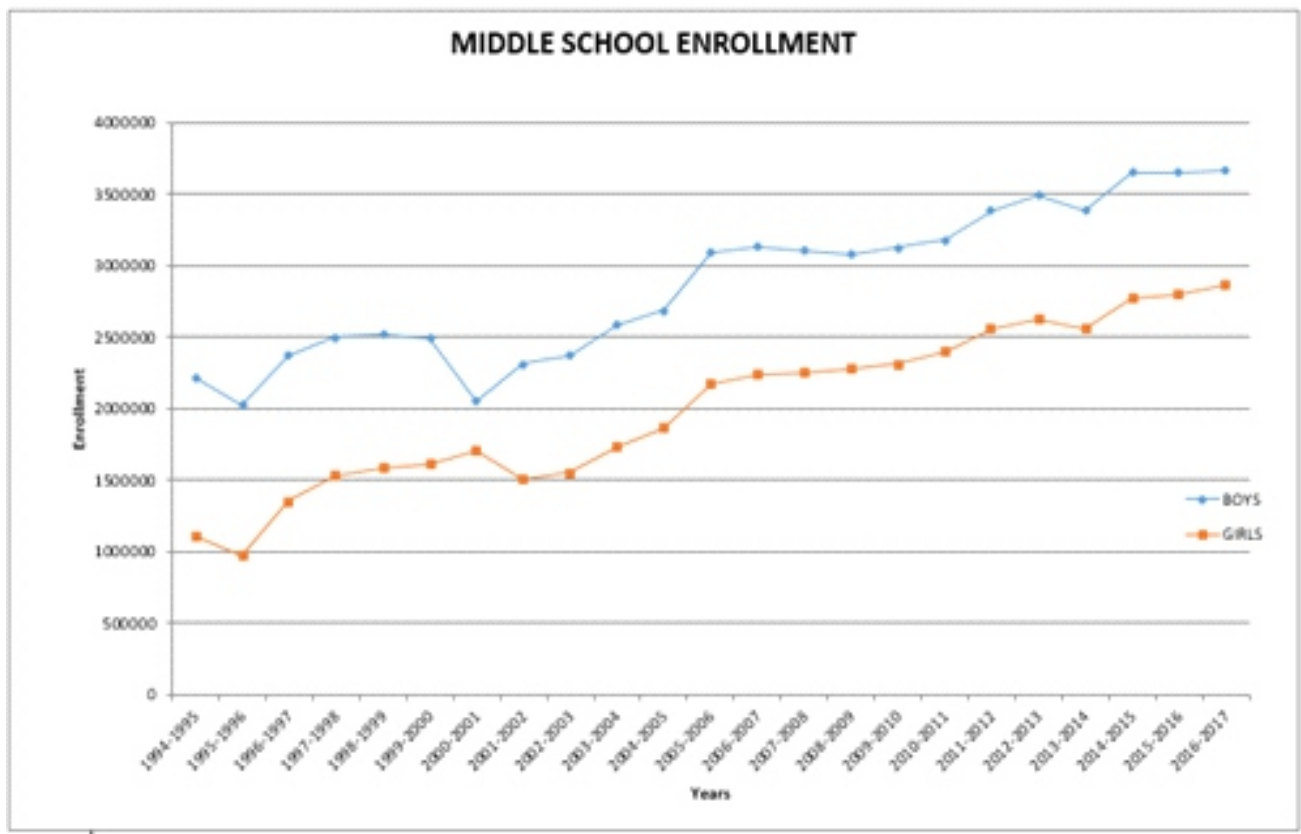

Figure.4: Pakistan Education Statics 2016

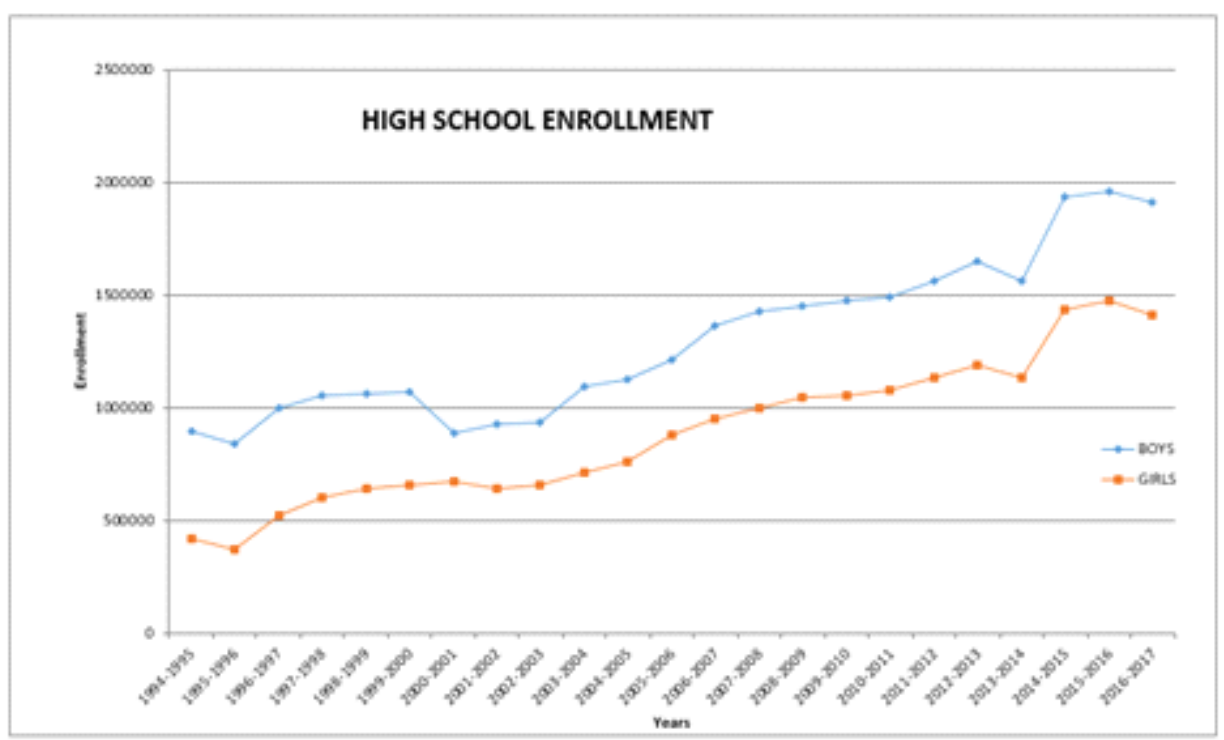

Figure.5: Pakistan Education Statics 2016

\section{Dropouts}

Where students are enrolled to acquire knowledge most of them are recorded to be dropout from school for the purpose of being highly demotivated or due to the environment of the school with punishment adding as one of the factors and no proper parenting with that child labor plays its part even as some are forced to work from the early age in order to earn an education is sacrificed. 
(Ahmaed, 2014).

\section{Budget Allocation}

With every year of budget some amount is budgeted to education as well which doesn't seems adequate to fill in the loops of the education system the governments has not increased more than $2.5 \%$ budget in the education sector, country like Pakistan needs more allocation as it is developing other regional countries like Sri Lanka and Bangladesh even have high budget allocation in the education sector one reason why their literacy rate have to tend to increase.(Ahmaed, 2014).

\section{RESEARCHACTIVITIES}

Research helps to evaluate the previous conditions and how to make them better by coming up with new methods here in Pakistan research activities are not promoted widely with less fundraising for research to evaluate areas to work on.(Rasool, 2007).

\section{EXAMINATIONS}

Exams are to check the learning ability of a student and evaluate. Here exams are done to test the memory of the students with no practical implementations of the study and no means evaluate the decision making the ability of the person. Moreover, unfair means of examinations are always encountered which demoralize those who will study.

\section{CONCLUSION}

This research paper reflects how educational challenges hinder the economic development of the country. It is true development relies on education and development of the person is the development of the country. To make a country economically stable it is best to work on its education sector which develops manpower and skill full people. The inadequate education system will never let a country grow in the right direction. The quality is what matters private education system should not be criticized as the reason for abandoning public education rather immense work should be done to be on the same page. The challenges of an education system can easily overcome if proper governance of this sector is done. Education should be the priority of the country in order to compete and withstand with other countries in terms of positive economic, social and political growth

\section{RECOMMENDATIONS}

Few recommendations to cater the challenges in the current education system are Teachers recruited must meet the eligibility criteria with a compulsorily certified program of teaching. It is to be the responsibility of government and schools to provide further mandatory training to teachers in order to enhance skills. Look over the teachers to avoid harsh behavior towards the students. There should be the single medium of instructions at all levels to accumulate uniformity, that is English/Urdu should be made the medium of instruction with no dual medium of instruction. Only one system of education should be widely promoted in entire Pakistan with no separate boards. Textbooks and curriculum should be revised on yearly basis to remain on the same page of education. Teachers should be motivated to make leanings with new techniques. Proper resources should be allocated with more work on the infrastructure of the schools and physicals facilities of electricity and proper classrooms which will make children willing to attend schools. The proper framework should be developed to look over the matter of child labor and promote education for them. Fee structures should be decreased to increase the affordability for the parents to educate their children this can be done when the amount of budget allocates to education sector increases. Students to be provided with scholarships from 
primary level with need-based concessions well. Extracurricular to be promoted widely as it adds on to the skills of the students and making the manpower in market wanting to work for economic development. Awareness programs should be initiated to educate the masses about the importance of both the gender being educated. Policies should be well implemented and evaluated to check how well the policy is. With technological advances, student's personality should be molded accordingly to cater to the needs of the world. Research areas should be promoted with more researches conducted in the education field to know the flaws and come up with its solutions.

\section{REFERENCES}

Role of Education in Globalization: A Case for Pakistan. (2005). SAARC Journal of Human Resource Development, 90-107.

Ahmaed, I. (2014). Critical analysis of education problems of Pakistan; Possible solutions. International Journal of evaluation and research education, 79-84.

Ahsan, M. (2003). An analytical review of Pakistan's educational policies and plans. 259-280.

Ashraf. (2016). Education and development of Pakistan: A study of the current situation of education and literacy in Pakistan. US-China Education Review B, 647-654.

Chisti, D. u. (2011). Quality school education in Pakistan; Challenges, Success, strategies.

Dean, B. L. (2005). Citizenship Education In Pakistani schools; Problems and possibilities. International Journal of Citizenship and Teacher Education, 35-55.

din, Z. u. (2013). education service delivery system by district government of Peshawar; parents perspective. Journal of managerial sciences, 233-241.

Dr. Khalid Rashid, S. M. (Novemember 2012). Education in Pakistan: Problems and their Solutions. International Journal of Academic Research in Business and Social Sciences, 332-343.

Farhat Saleem, Z. N. (December 2013). School Effectiveness in Pakistan: A Gender Perspective. Journal of Research and Reflections in Education, 33-142.

Hina Rehman, D. N. (2011). Flaws in Pakistan's Educational System. Abasyn Journal of Social Sciences; $70-83$.

Hussain, D. I. (2012). Education reforms in Pakistan. Policy Dialogue. Islamabad.

Kazm, S. W. (2005). Role of Education in Globalization: A Case for Pakistan. SAARC Journal of Human Resource Development, 90-107.

Khan, A. J. (2008). Pays off to schooling and return to credentials. SPDC.

Rasool, G. (2007). education in Pakistan; key issues, problems and the new challenges. Journal of Management and social science, 47-55.

Samina Malik, K. C. (Januaury 2011). Higher education and women's empowerment in Pakistan. Routledge, 29-45.

Sattar, T. (2012 March). "A Sociological Analysis of Stumbling Blocks in Structure of Education Sector: A Case. International research of humanities and social sciences, 96-110.

Shamim, F. (2008). Trends, issues and challenges in English language. Asia Pacific Journal of Education, 235-239.

Zaidi, S. (2015). Issues in Pakistan's economy. Oxford University Press. 